\title{
Alzheimer's Disease Biomarkers Have Distinct Associations with Specific Hippocampal Subfield Volumes
}

\author{
Citation for published version (APA):
}

Muller-Ehrenberg, L., Riphagen, J. M., Verhey, F. R. J., Sack, A. T., Jacobs, H. I. L., \& Alzheimer's Disease Neuroimaging Initiative (2018). Alzheimer's Disease Biomarkers Have Distinct Associations with Specific Hippocampal Subfield Volumes. Journal of Alzheimer's Disease, 66(2), 811-823. https://doi.org/10.3233/JAD-180676

\section{Document status and date: \\ Published: 01/01/2018}

DOI:

10.3233/JAD-180676

\section{Document Version:}

Publisher's PDF, also known as Version of record

\section{Document license:}

Taverne

\section{Please check the document version of this publication:}

- A submitted manuscript is the version of the article upon submission and before peer-review. There can be important differences between the submitted version and the official published version of record. People interested in the research are advised to contact the author for the final version of the publication, or visit the DOI to the publisher's website.

- The final author version and the galley proof are versions of the publication after peer review.

- The final published version features the final layout of the paper including the volume, issue and page numbers.

Link to publication

\footnotetext{
General rights rights.

- You may freely distribute the URL identifying the publication in the public portal. please follow below link for the End User Agreement:

www.umlib.nl/taverne-license

Take down policy

If you believe that this document breaches copyright please contact us at:

repository@maastrichtuniversity.nl

providing details and we will investigate your claim.
}

Copyright and moral rights for the publications made accessible in the public portal are retained by the authors and/or other copyright owners and it is a condition of accessing publications that users recognise and abide by the legal requirements associated with these

- Users may download and print one copy of any publication from the public portal for the purpose of private study or research.

- You may not further distribute the material or use it for any profit-making activity or commercial gain

If the publication is distributed under the terms of Article $25 \mathrm{fa}$ of the Dutch Copyright Act, indicated by the "Taverne" license above, 


\title{
Alzheimer's Disease Biomarkers Have Distinct Associations with Specific Hippocampal Subfield Volumes
}

\author{
Lisa Müller-Ehrenberg ${ }^{\mathrm{a}, *}$, Joost M. Riphagen ${ }^{\mathrm{a}}$, Frans R.J. Verhey ${ }^{\mathrm{a}}$, Alexander T. Sack ${ }^{\mathrm{b}}$ \\ and Heidi I.L. Jacobs ${ }^{\mathrm{a}, \mathrm{b}, \mathrm{c}, *}$ for the Alzheimer's Disease Neuroimaging Initiative ${ }^{1}$ \\ ${ }^{a}$ Faculty of Health, Medicine and Life Sciences, School for Mental Health and Neuroscience, \\ Alzheimer Centre Limburg, Maastricht University, Maastricht, The Netherlands \\ ${ }^{\mathrm{b}}$ Department of Cognitive Neuroscience, Faculty of Psychology and Neuroscience, Maastricht University, \\ Maastricht, The Netherlands \\ ${ }^{\mathrm{c}}$ Department of Radiology, Division of Nuclear Medicine and Molecular Imaging, Massachusetts \\ General Hospital/Harvard Medical School, Boston, MA, USA
}

Accepted 3 September 2018

\begin{abstract}
Measures of amyloid- $\beta(\mathrm{A} \beta)$ and phosphorylated tau (p-tau) concentrations in cerebrospinal fluid are extensively used for diagnostic and research purposes in Alzheimer's disease (AD) as correlates of cortical thinning and cognitive outcomes. The present study investigated the relationship of $\mathrm{A} \beta$ and $\mathrm{p}$-tau with hippocampal subfield volumes Cornu Ammonis (CA) 1-4, dentate gyrus (DG), and subiculum. Subfields were segmented from T1-weighted images from the ADNI-population using FreeSurfer v6. Linear and polynomial regression models revealed distinct associations of A $\beta$ and p-tau with subfield volumes. $A \beta$ had a quadratic relationship with all hippocampal subfield volumes and the inflection point was higher than the validated cut-off for $A \beta$. For $p$-tau the relationships were linear, except for CA3, in which it was quadratic. For the CA1 and CA3, these quadratic relationships with $\mathrm{A} \beta$ were only observed when p-tau was low. Amyloid and p-tau contributed equally to the explained variance in CA4 and DG volume. Subicular volume was best explained by A $\beta$ alone. These biomarker relationships with hippocampal subfield volumes seem to mirror the hippocampal-specific topography of $\mathrm{A} \beta$ and tau reported in neuropathological staging models. In addition, using continuous values of $\mathrm{A} \beta$ reveals positive patterns with imaging markers for individuals around the positivity threshold that would be masked when using dichotomized biomarker groups, which can be important for early detection and accurate inclusion of potential participants at risk for AD in clinical trials.
\end{abstract}

Keywords: Aging, Alzheimer's disease, amyloid, hippocampus, polynomial, subfields, tau

\footnotetext{
${ }^{1}$ Data used in preparation of this article were obtained from the Alzheimer 's disease Neuroimaging Initiative (ADNI) database (http://adni.loni.usc.edu). As such, the investigators within the ADNI contributed to the design and implementation of ADNI and/or provided data but did not participate in analysis or writing of this report. A complete listing of ADNI investigators can be found at: http://adni.loni.usc.edu/wp-content/ uploads/how_to_apply/ADNI_Acknowledgement_List.pdf.

*Correspondence to: Heidi Jacobs, School for Mental Health and Neuroscience, Alzheimer Centre Limburg, Maastricht University, Uns40 Box 34, PO BOX 616, 6200 MD Maastricht, The
}

\section{INTRODUCTION}

Alzheimer's disease (AD), the most prevalent form of dementia [1], is characterized by two neuropathological hallmarks, the accumulation of amyloid- $\beta$

Netherlands. E-mail: h.jacobs@maastrichtuniversity.nl and Lisa Müller-Ehrenberg, School for Mental Health and Neuroscience, Alzheimer Centre Limburg, Maastricht University, Uns40 Box 34, PO BOX 616, 6200 MD Maastricht, The Netherlands. Tel.: +31 43 388 1025; E-mail: 1.muller-ehrenberg@ maastrichtuniversity.nl. 
(Aß) deposits and neurofibrillary tau tangles [2], which ultimately lead to neuronal atrophy and cognitive decline.

Accumulation of $\mathrm{A} \beta$ has been associated with cortical thinning in healthy older adults and patients with mild cognitive impairment (MCI) and dementia of AD-type [3-5], although other studies reported higher levels of cortical thickness with greater $\mathrm{A} \beta$ deposition [6,7]. These inconsistencies may be resulting from potential nonlinear relationships between $A \beta$ and cortical thickness. In line with this notion, Fortea and colleagues observed a non-linear association between $A \beta$ and thickness in various regions across the cortical mantle, especially for $A \beta$ values surrounding the cut-off values for $A \beta$ positivity [8]. This suggests that dichotomizing $A \beta$ when investigating associations with brain structure may conceal important patterns, especially in individuals surrounding the threshold and who are thus more likely to convert to prodromal AD over time [9]. Interestingly, in a follow-up study, Fortea and colleagues [10] showed that cortical thickening in relation to $A \beta$ was observed when cerebrospinal fluid (CSF) p-tau levels were normal, suggesting that increases in $A \beta$-related cortical thickness reflect ongoing aberrant processes that may be below our detection level. When p-tau levels increase in the presence of $A \beta$ deposits, atrophy sets in, suggesting that both pathologies act independently on the same biological pathological processes. Interestingly, these patterns may be regionally distinct and recent work by d'Oleire Uquillas and colleagues showed negative effects of $A \beta$ PET-deposition on several frontal and tempoparietal regions, but no associations were observed in the medial temporal lobe (MTL) [11].

The MTL is an interesting region as it is the first region accumulating tau pathology $[12,13]$. Autopsy studies have shown that low levels of Braak stage I-II tau pathology can occur in the MTL without presence of $A \beta$ deposits $[12,14]$. However, around Braak stage III, when tau pathology has progressed to the hippocampus, $A \beta$ is widespread in the brain in the majority of the individuals [15]. These individuals without any cognitive deficits, are considered to be in the preclinical phase of AD. Notably, pathology in the hippocampus has a very specific topography, with tau pathology affecting the Cornu Ammonis 1 (CA1) and dentate gyrus (DG) and $A \beta$ affecting the $\mathrm{CA} 1$, subiculum and presubiculum prior to the other subfields [2, 16].

In vivo MRI studies have shown that higher CSF p-tau levels or elevated $A \beta-P E T$ binding correlated with lower overall hippocampal volume in patients along the $\mathrm{AD}$ continuum $[17,18]$. With respect to hippocampal subfield volumes, patients with mild cognitive impairment (MCI) showed lower CA1 volume compared to healthy controls, but this volume difference did not correlate with $A \beta$, suggesting that $\mathrm{CA} 1$ volume is affected by non-specific ageingrelated neurodegeneration [19]. In preclinical and prodromal $\mathrm{AD}$, reduced subiculum volume has been linked to abnormal $A \beta[20,21]$, but there is evidence suggesting that $A \beta$ is not sufficient and that abnormal tau is also necessary for subfield atrophy [21]. Additive effects of $A \beta$ and tau have also been shown for total hippocampus volume in a sample consisting of cognitively normal individuals, MCI and AD patients [22].

Given the previous findings of curvilinear associations between $A \beta$ and thickness in cortical regions as well as the distinct temporal and spatial biomarker patterns in the hippocampal subfields, we set out to investigate whether the relationship between $A \beta$ or p-tau can be described in a linear or curvilinear manner for specific hippocampal subfield volumes. In addition, we aimed to investigate whether $\mathrm{A} \beta$ and tau contribute additively or synergistically to distinct hippocampal subfield volumes.

Understanding the relationship between hippocampal subfield volume and $\mathrm{AD}$ biomarkers is important, as the hippocampus is considered to be a vital structure for the transition to prodromal AD. In addition, studies investigating pharmacological interventions for $\mathrm{AD}$ often base inclusion criteria on biomarker information including hippocampal volume. Therefore, more detailed information on how biomarkers relate to the hippocampus may improve selection of target groups.

\section{METHODS}

Data used in this article were obtained from the ADNI database (http://adni.loni.usc.edu). ADNI was launched in 2003, led by Principal Investigator Michael W. Weiner, MD. The main goal of ADNI has been to test whether magnetic resonance imaging, positron emission tomography, other biological markers, and clinical and neuropsychological assessment can be combined to measure the progression of MCI and $\mathrm{AD}$. For up-to-date information, see http://www.adni-info.org. 


\section{Participants}

Diagnostic procedure, clinical characterization, CSF biomarker and imaging acquisition, and cognitive testing procedures for ADNI are described extensively elsewhere [23]. This study is part of a larger project within the ADNI-database, where we are investigating longitudinal trajectories of biomarkers. For the current study, we report on the cross-sectional data. Inclusion-criteria for this study were presence of CSF-A $\beta$, CSF-p-tau measures, and structural T1-weighted MR-images.

A subset of the ADNI1-population was chosen for this study, with CSF at baseline and 3T T1-weighted MRI-scans, being the main selection criteria. Only participants with CSF-measures of both $A \beta$ and ptau were included in the selection. This resulted in a total of 45 cognitively normal $(\mathrm{CN}), 70$ patients with $\mathrm{MCI}$, and 13 patients with $\mathrm{AD}$, following the criteria described in Petersen et al. [23].

\section{Ethics approval and informed consent}

ADNI is a multi-site investigation. All ADNI sites obtained Institutional Review Board approval for the use of humans for research from their respective Institutional Review Board within 5 months of receiving the final protocol and all participants provided written informed consent.

\section{CSF analyses}

The ADNI procedures and methods for acquisition of CSF and biomarker measurement have been previously reported [24]. Multiplex xMAP Luminex platform (Luminex Corporation, Austin, TX) with INNO-BIA AlzBio3 (Innogenetics, Ghent, Belgium) immunoassay kit-based reagents were used to measure $A \beta$ and p-tau. P-tau was chosen as measure of neurodegeneration as it has previously been shown to be more specific to AD-pathology than total tau, which more likely is a measure of overall neurodegeneration [25]. P-tau is highly correlated with total tau (in our sample: $r=0.8, p \leq 0.001$ ).

\section{Hippocampal subfield segmentation}

Segmentation of hippocampal subfields was carried out automatically from the T1-weighted images with FreeSurfer version 6.0, using the built-in automated reconstruction process [26-29]. Technical details of these procedures are described extensively in prior publications [30-32]. To summarize, intensity normalization of the T1-weighted images, skull-stripping, segregation of left and right hemispheres, removal of brainstem and cerebellum, correction for topology defects, definition of the borders of grey and white matter, and of grey matter and CSF, and parcellation of cortical and subcortical regions are part of the process.

The current version of FreeSurfer uses a Bayesian inference approach combined with a novel atlas algorithm of the hippocampal formations, based on an ultra-high resolution (voxel size $0.12 \mathrm{~mm}$ isotropic) ex vivo MRI atlas created from autopsy brains. This technique was validated in an independent in vivo $1 \mathrm{~mm}$ MRI resolution data-set of 39 individuals and was shown to be superior to its predecessor (FreeSurfer v.5.0.3) that was based on in vivo data only. Using FreeSurfer's native visualization toolbox, we visually inspected and, if necessary, edited each image for over- or under-estimation of the gray/white matter boundaries and to identify brain areas erroneously excluded during skull stripping (JMR). In addition, we checked if the hippocampal subregion mask was well positioned. Finally, we checked the ranking of the subregion volumes. For the subregions of interests, CA1 volume was expected to be the largest and CA3 the smallest.

Subfields considered in the analyses are CA1, CA3, CA4, DG, and subiculum, as they have previously been associated with volumetric changes in the disease progression of AD [33]. Subfield volume was expressed as actual volume divided by intracranial volume, multiplied by 100000 , consistent with other studies [34]. Left and right hemispheres were summed together. A graphical visualization of the hippocampal subfields segmentations for one participant can be found in Fig. 1.

\section{Statistical analyses}

All statistical analyses were performed with $\mathrm{R}$ software version 3.5.0 (http://www.r-project.org). Descriptive information on the total sample was assessed with mean and standard deviation. Differences between the clinical groups concatenated in the current work are assessed with ANOVA (and post hoc comparisons) for continuous variables and Chi-square for dichotomous variables. Linear and polynomial regression models were fitted to assess the relationship between $A \beta$ and hippocampal subfield volumes, and p-tau and hippocampal subfield volumes, respectively. Linear and quadratic fits were 


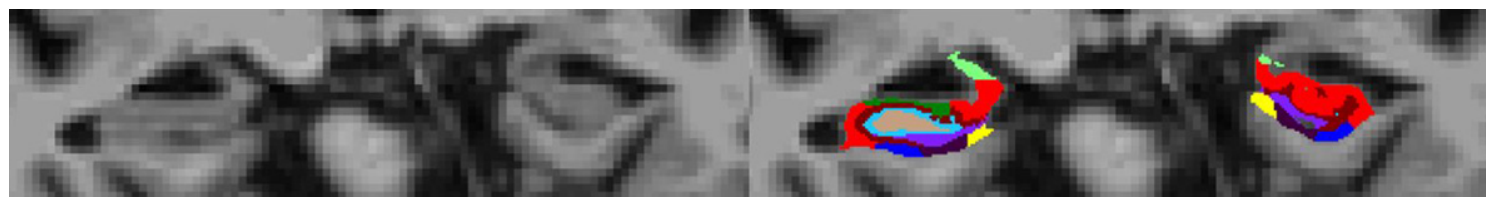

Fig. 1. Visualization of the hippocampal subfields segmentation obtained from FreeSurfer v6, coronal view. The right side contains the color-coded segmentation of subfields parasubiculum (yellow), presubiculum (dark purple), subiculum (dark blue), CA1 (red), CA3 (green), CA4 (beige), DG (light blue), and molecular layer (burgundy). The left side shows the same view without overlaid segmentations.

Table 1

Demographic description of sample

\begin{tabular}{|c|c|c|c|c|c|c|c|}
\hline & \multirow{2}{*}{$\begin{array}{c}\text { Entire } \\
\text { sample } \\
\mathrm{N}=128\end{array}$} & \multirow{2}{*}{$\begin{array}{c}\mathrm{CN} \\
\mathrm{N}=45\end{array}$} & \multirow{2}{*}{$\begin{array}{c}\text { MCI } \\
\mathrm{N}=70\end{array}$} & \multirow{2}{*}{$\begin{array}{c}\text { AD } \\
N=13\end{array}$} & \multicolumn{2}{|c|}{ Group differences } & \multirow{2}{*}{$\begin{array}{c}\text { Directionality of } \\
\text { effect }\end{array}$} \\
\hline & & & & & $\mathrm{F}$ & $p$ & \\
\hline Age & $75.64(6.1)$ & $76.36(4.9)$ & $75.24(6.8)$ & $75.36(5.9)$ & 0.41 & 0.802 & \\
\hline Sex (female) & $86(42)$ & $27(18)$ & $54(16)$ & $5(8)$ & $13.02 \Delta$ & $0.011^{*}$ & $\mathrm{CN}<\mathrm{MCI}>\mathrm{AD}$ \\
\hline Education (y) & $16.01(2.9)$ & $15.86(3.2)$ & $16.2(2.6)$ & $15.53(2.9)$ & 0.79 & 0.531 & \\
\hline MMSE & $27.49(2.1)$ & $29.24(0.8)$ & 26.95 (1.6) & $24.31(1.6)$ & 36.74 & $<0.0001^{*}$ & $\mathrm{CN}>\mathrm{MCI}>\mathrm{AD}$ \\
\hline CDR-sum of Boxes & $1.23(1.39)$ & $0.01(0.1)$ & $1.51(0.8)$ & $4.03(1.5)$ & 75.39 & $<0.0001 *$ & $\mathrm{CN}<\mathrm{MCI}<\mathrm{AD}$ \\
\hline $\mathrm{A} \beta(\mathrm{mg} / \mathrm{pl})$ & $173.34(57.5)$ & $208.2(51.5)$ & $158.86(54.4)$ & $130.61(23.6)$ & 136.1 & $<0.0001 *$ & $\mathrm{CN}>\mathrm{MCI}=\mathrm{AD}$ \\
\hline P-tau $(\mathrm{mg} / \mathrm{pl})$ & $30.64(14.9)$ & $22.86(10.5)$ & $33.54(15.3)$ & $42(14.4)$ & 24.39 & $<0.0001 *$ & $\mathrm{CN}<\mathrm{MCI}=\mathrm{AD}$ \\
\hline CA1 & $0.67(0.1)$ & $0.75(0.1)$ & $0.63(0.1)$ & $0.59(0.1)$ & 14.48 & $<0.0001^{*}$ & $\mathrm{CN}>\mathrm{MCI}=\mathrm{AD}$ \\
\hline CA3 & $0.23(0.1)$ & $0.25(0.1)$ & $0.22(0.1)$ & $0.21(0.1)$ & 11.46 & $<0.0001 *$ & $\mathrm{CN}>\mathrm{MCI}=\mathrm{AD}$ \\
\hline CA4 & $0.27(0.1)$ & $0.31(0.1)$ & $0.26(0.1)$ & $0.24(0.1)$ & 13.14 & $<0.0001 *$ & $\mathrm{CN}>\mathrm{MCI}=\mathrm{AD}$ \\
\hline DG & $0.31(0.1)$ & $0.35(0.1)$ & $0.29(0.1)$ & $0.27(0.1)$ & 13.04 & $<0.0001 *$ & $\mathrm{CN}>\mathrm{MCI}=\mathrm{AD}$ \\
\hline Subiculum & $0.44(0.1)$ & $0.51(0.1)$ & $0.41(0.1)$ & $0.38(0.1)$ & 13.08 & $<0.0001 *$ & $\mathrm{CN}>\mathrm{MCI}=\mathrm{AD}$ \\
\hline Total Hippocampus & $3.58(0.6)$ & $4.05(0.4)$ & $3.36(0.5)$ & $3.13(0.4)$ & 15.22 & $<0.0001^{*}$ & $\mathrm{CN}>\mathrm{MCI}=\mathrm{AD}$ \\
\hline
\end{tabular}

CN, cognitively normal; MCI, mild cognitive impairment; AD, Alzheimer's disease; MMSE, Mini-Mental State Examination; CDR, Clinical Dementia Rating Scale; Subfield volume was expressed as actual volume divided by intracranial volume, multiplied by 100000; Group comparisons are corrected with the Bonferroni correction method for multiple comparisons; $\Delta$ Group differences for Sex were tested with a Chi-square test, *significant difference.

compared with the F-statistic for nested models. Models were corrected for age, sex, and Mini-Mental State Examination score (MMSE). MMSE score was added to the model as an indicator of disease severity, to ensure that our effects were not driven by diagnostic or clinical differences across the individuals. $A \beta$ and $p$-tau were treated as continuous variables. For comparability to previous work of Fortea and colleagues [10], we also ran models with p-tau as dichotomous variable based on published cut-off values [24]. Education did not contribute significantly, thus it was not added to the models. The validity of testing polynomial relationships is currently under debate and therefore, we also performed the twolines test [35]. The two-lines test searches the data for quadratic effects (e.g., an increase in slope followed by a decrease), and we will consider these results to be a validation of potential quadratic effects. To ensure that these effects were not driven by the AD cases, we repeated our analyses excluding the AD patients. Finally, additive and interactive effects were investigated by adding dichotomous $\mathrm{p}$-tau to the polynomial models with $A \beta$, and also the interaction between $A \beta$ and $p$-tau. An alpha-level of significance of 0.05 was chosen. Multiple comparison correction was done using the false discovery rate (FDR) approach [36].

\section{RESULTS}

A total of 128 (72 female) participants were included in the analysis $(\mathrm{CN}=45, \mathrm{MCI}=70$, and $\mathrm{AD}=13$ ). A full description of the demographic data for the entire group and for the respective patient groups can be found in Table 1. Briefly, the total group had a mean age of 75.6 years $(s d=6.1$, range: 61 to $89.6), 16.1$ years of education ( $s d=2.9$, range: 6 to $20)$, a mean MMSE score of 27.49 ( $s d=2.1$, range: 21 to 30), a mean Clinical dementia rating sum of boxes (CDR-SB) score of $1.23(s d=1.39$, range: 0 to 7 ), mean CSF-A $\beta$ values of $173.34 \mathrm{mg} / \mathrm{pl}(s d=57.5$, range: 76 to 300 ), and mean CSF-p-tau values of $30.64 \mathrm{mg} / \mathrm{pl}(s d=14.9$, range: 9 to 69$)$. 
Table 2

Non-linear association between $A \beta$ and hippocampal subfield volume

\begin{tabular}{llccccc}
\hline & Model & Estimate & Std-Error & $\mathrm{t}$ & $\begin{array}{c}\mathrm{p} \text { (FDR- } \\
\text { corrected) }\end{array}$ & $\begin{array}{c}\text { Model } \\
\text { comparisons (F) }\end{array}$ \\
\hline CA1 & Linear & 0.066 & 0.018 & 3.59 & $<0.001^{*}$ & \\
& Quadratic & $6.620 \times 10^{-4}$ & $3.219 \times 10^{-4}$ & 2.05 & $0.041^{*}$ & $4.23^{*}$ \\
CA3 & Linear & 0.017 & 0.007 & 2.53 & $0.012^{*}$ & \\
& Quadratic & $-3.55 \times 10^{-4}$ & $1.168 \times 10^{-4}$ & 3.04 & $0.008^{*}$ & $9.26^{*}$ \\
CA4 & Linear & 0.019 & 0.007 & 2.78 & $0.009^{*}$ & \\
DG & Quadratic & $-3.723 \times 10^{-4}$ & $1.256 \times 10^{-4}$ & 2.96 & $0.008^{*}$ & $8.78^{*}$ \\
Subiculum & Linear & 0.023 & 0.008 & 2.69 & $0.009^{*}$ & \\
& Quadratic & $-4.239 \times 10^{-4}$ & $1.469 \times 10^{-4}$ & 2.88 & $0.008^{*}$ & $8.33^{*}$ \\
Total Hippocampus & Linear & 0.042 & 0.013 & 3.08 & $0.004^{*}$ & \\
& Quadratic & $-5.152 \times 10^{-4}$ & $2.393 \times 10^{-4}$ & 2.15 & $0.039^{*}$ & $4.63^{*}$ \\
& Linear & 0.301 & 0.092 & 3.24 & $0.004^{*}$ & \\
& Quadratic & $-4.120 \times 10^{-3}$ & $1.606 \times 10^{-3}$ & 2.56 & $0.016^{*}$ & $6.57^{*}$ \\
\hline
\end{tabular}

Note: Regression models to determine the effect of $A \beta$ on hippocampal subfield volume. Models tested were linear models and quadratic models. Covariates in all models were age, sex and MMSE score. Estimates are the unstandardized beta-coefficients.

Table 3

$\mathrm{A} \beta$ has a u-shaped relationship with hippocampal subfield volumes

\begin{tabular}{|c|c|c|c|c|c|}
\hline & \multicolumn{2}{|c|}{$\begin{array}{c}\text { Line } 1 \\
\text { (positive) }\end{array}$} & \multicolumn{2}{|c|}{$\begin{array}{c}\text { Line } 2 \\
\text { (negative) }\end{array}$} & \multirow[t]{2}{*}{$\begin{array}{c}\text { Inflection } \\
\text { point }\end{array}$} \\
\hline & $\mathrm{Z}$ & $\mathrm{p}$ & $\mathrm{Z}$ & $\mathrm{p}$ & \\
\hline$\overline{\mathrm{CA} 1}$ & 3.74 & $<0.001$ & -2.97 & 0.003 & 210.58 \\
\hline CA3 & 4.05 & $<0.001$ & -3.7 & $<0.001$ & 214.28 \\
\hline CA4 & 3.94 & $<0.001$ & -3.73 & $<0.001$ & 217.76 \\
\hline DG & 3.78 & $<0.001$ & -3.59 & $<0.001$ & 217.8 \\
\hline Subiculum & 3.11 & 0.002 & -2.34 & 0.019 & 210.56 \\
\hline Total Hippocampus & 3.63 & $<0.001$ & -3.13 & 0.002 & 211.78 \\
\hline
\end{tabular}

Note: The two-lines test was used to test whether A $\beta$ has a u-shaped effect on hippocampal subfield volumes. Covariates added to these models are age, sex, and MMSE score.

\section{Relationships between hippocampal subfield volumes $A \beta$}

Table 2 shows the results for linear and quadratic relationships between $A \beta$ and subfield volume. The F-test comparing the models indicated that quadratic models described the data best for all subfields. Scatterplots visualizing the polynomial relationship between $\mathrm{A} \beta$ and hippocampal subfield volumes can be found in Supplementary Fig. 1.

To test the robustness of these polynomial effects, we performed the two-lines test, which confirmed that there were $\mathrm{u}$-shaped effects of $\mathrm{A} \beta$ on all subfields (Table 3 and Fig. 2). It should be noted, that in this sample the observed inflection-point in the two-lines test results, was detected above the cut-off of 192 $\mathrm{pg} / \mathrm{ml}$ for $\mathrm{A} \beta$ defined in ADNI (range 210.58-217.8 depending on the subfield).

Excluding the $\mathrm{AD}$ cases from our data did not alter the above results. The statistics of the polynomial regression models and two-lines test without the AD cases is provided in Supplementary Table 1 and Table 4.

\section{Relationships between hippocampal subfield volumes and p-tau}

Model comparisons of the polynomial regressions indicated that in all subfields the linear model described the data better than the quadratic model with the exception of $\mathrm{CA} 3$, in which a quadratic model fitted the data best: $(\mathrm{F}=4.64, p=0.033)$, (see Table 4 and Fig. 3). The results from the two-lines test confirmed that there was no u-shaped association between p-tau and any hippocampal subfield volumes (see Supplementary Table 4).

Excluding the AD cases from our data showed similar relationships as in the full sample described above (see Supplementary Table 3).

\section{Additive versus interactive effects of $A \beta$ and p-tau on hippocampal subfield volumes}

In an attempt to replicate the work from Fortea [10], we included p-tau as a dichotomous variable in the same model as polynomial $A \beta . A \beta$ and p-tau both contributed significantly to the associations with 

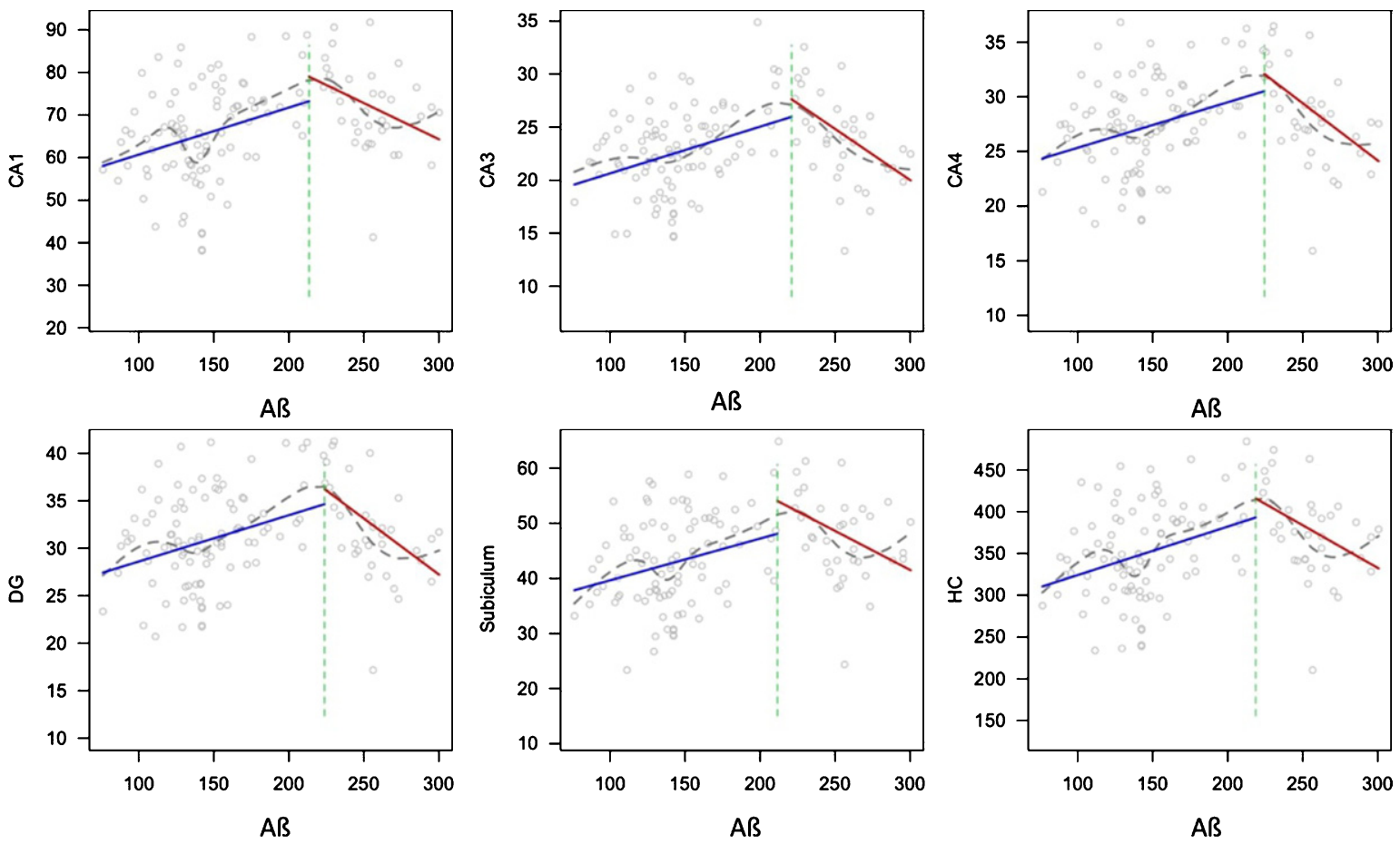

Fig. 2. Two-lines test plots showing the $\mathrm{u}$-shaped association between $\mathrm{A} \beta$ and all hippocampal subfield volumes. Volumes are corrected for intracranial volume. The blue line shows the first, ascending line, which is followed by the red, descending line. The green dotted line shows the inflection-point of the curve. The grey line shows a loess function.

Table 4

Association between p-tau and hippocampal subfield volume

\begin{tabular}{|c|c|c|c|c|c|c|}
\hline & Model & Estimate & $\begin{array}{l}\text { Std- } \\
\text { Error }\end{array}$ & $\mathrm{t}$ & $\begin{array}{c}\mathrm{p}(\mathrm{FDR}- \\
\text { corrected) }\end{array}$ & $\begin{array}{c}\text { Model } \\
\text { comparisons } \\
(\mathrm{F}) \\
\end{array}$ \\
\hline \multirow[t]{2}{*}{ CA1 } & Linear & -0.225 & 0.069 & 3.25 & $0.003 *$ & \\
\hline & Quadratic & 0.006 & 0.004 & 1.71 & 0.116 & 2.91 \\
\hline \multirow[t]{2}{*}{ CA3 } & Linear & -0.081 & 0.024 & 3.24 & $0.003 *$ & \\
\hline & Quadratic & 0.003 & 0.001 & 2.15 & $0.033 *$ & $4.64 *$ \\
\hline \multirow[t]{2}{*}{ CA4 } & Linear & -0.080 & 0.027 & 2.97 & $0.004 *$ & \\
\hline & Quadratic & 0.003 & 0.001 & 1.87 & 0.116 & 3.51 \\
\hline \multirow[t]{2}{*}{ DG } & Linear & -0.096 & 0.031 & 3.05 & $0.003 *$ & \\
\hline & Quadratic & 0.003 & 0.002 & 1.78 & 0.116 & 3.18 \\
\hline \multirow[t]{2}{*}{ Subiculum } & Linear & -0.129 & 0.051 & 2.51 & $0.013 *$ & \\
\hline & Quadratic & 0.003 & 0.003 & 1.01 & 0.311 & 1.03 \\
\hline \multirow[t]{2}{*}{ Total Hippocampus } & Linear & -1.061 & 0.346 & 3.06 & $0.003 *$ & \\
\hline & Quadratic & 0.035 & 0.021 & 1.69 & 0.116 & 2.85 \\
\hline
\end{tabular}

Note: Regression models to determine the effect of p-tau on hippocampal subfield volume. Models tested were linear models and quadratic models. Covariates in all models were age, sex, and MMSE score. Estimates are the unstandardized beta-coefficients.

subfield volumes CA4 and DG. In the subiculum and total $\mathrm{HC} \mathrm{A} \beta$ was the strongest predictor of subfield volume (see Table 5 for detailed results).

We observed significant interactions between quadratic $A \beta$ and dichotomous $p$-tau in subfields CA1 and CA3, but not for the other subfields (see Table 5 for an overview, and Fig. 4). In both CA1 and CA3, only participants with low p-tau levels had a significant quadratic association between $A \beta$ and subfield volume. Polynomial $A \beta$ models including the interaction term were superior to linear models.

Excluding the AD cases from our data did not change the relationships observed with $\mathrm{AD}$ cases included (data not shown). 

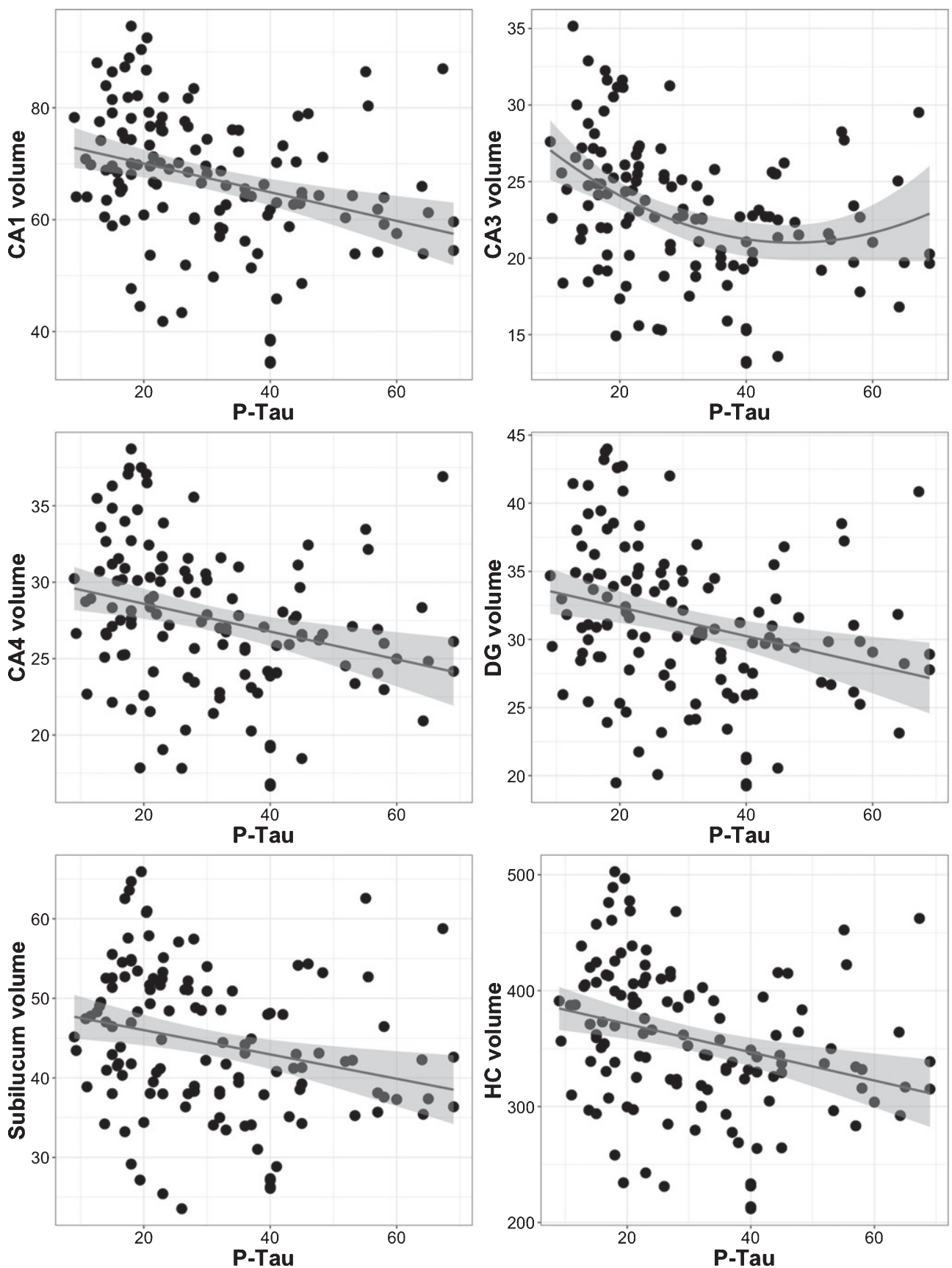

Fig. 3. Scatterplots showing the relationship between p-tau and hippocampal subfield volume using polynomial regression analyses. Volumes are corrected for intracranial volume. CA3 has a quadratic relationship with p-tau, while the relationship is linear for the remaining subfields (see also Table 4).

Post-hoc analyses: Sample differences between the validated $A \beta$ cut-off and the data-driven cut-off

As the two-lines function calculated the inflection point for $\mathrm{A} \beta$ above the validated threshold for
$\mathrm{A} \beta$ positivity in ADNI, we investigated the characteristics of individuals between these two cut-points post-hoc. Non-parametric Wilcox Rank tests revealed that the participants with MCI $(n=4)$ that would be considered to be in the normal range for $\mathrm{A} \beta$ negative according to the predefined cut-off $(192 \mathrm{mg} / \mathrm{pl})$ 
Table 5

Additive and interactive effects of $\mathrm{A} \beta$ and dichotomous p-tau on subfield volume

\begin{tabular}{|c|c|c|c|c|c|}
\hline & & Estimate & Std-Error & $\mathrm{t}$ & $p$ \\
\hline \multirow[t]{3}{*}{$\overline{\mathrm{CA} 1}$} & $A \beta^{2}$ & $<-0.001$ & $<0.001$ & 2.17 & $0.032 *$ \\
\hline & p-tau dichotomous & -5.401 & 3.143 & 1.71 & 0.088 \\
\hline & $\mathrm{A} \beta^{2} * \mathrm{p}$-tau dichotomous & 0.004 & 0.002 & 2.11 & $0.036 *$ \\
\hline \multirow[t]{3}{*}{ CA3 } & $A \beta^{2}$ & $<-0.001$ & $<0.001$ & 3.33 & $0.001 *$ \\
\hline & p-tau dichotomous & -3.528 & 1.109 & 3.18 & $0.002 *$ \\
\hline & $\mathrm{A} \beta^{2} * \mathrm{p}$-tau dichotomous & 0.001 & 0.001 & 2.04 & $0.043 *$ \\
\hline \multirow[t]{3}{*}{ CA4 } & $\mathrm{A} \beta^{2}$ & $<-0.001$ & $<0.001$ & 3.18 & $0.002 *$ \\
\hline & p-tau dichotomous & -3.179 & 1.207 & 2.63 & $0.009 *$ \\
\hline & $\mathrm{A} \beta^{2} * \mathrm{p}$-tau dichotomous & 0.002 & 0.001 & 1.56 & 0.120 \\
\hline \multirow[t]{3}{*}{ DG } & $\mathrm{A} \beta^{2}$ & $<-0.001$ & $<0.001$ & 3.10 & $0.002 *$ \\
\hline & p-tau dichotomous & -3.697 & 1.412 & 2.61 & $0.009 *$ \\
\hline & $\mathrm{A} \beta^{2} * \mathrm{p}$-tau dichotomous & 0.001 & 0.001 & 1.54 & 0.126 \\
\hline \multirow[t]{3}{*}{ Subiculum } & $A \beta^{2}$ & -0.001 & $<0.001$ & 2.20 & $0.029 *$ \\
\hline & p-tau dichotomous & -2.325 & 2.356 & 0.95 & 0.326 \\
\hline & $\mathrm{A} \beta^{2} * \mathrm{p}$-tau dichotomous & 0.003 & 0.001 & 1.25 & 0.210 \\
\hline \multirow[t]{3}{*}{ Total Hippocampus } & $\mathrm{A} \beta^{2}$ & -0.005 & 0.002 & 2.68 & $0.008 *$ \\
\hline & p-tau dichotomous & -27.89 & 15.67 & 1.78 & 0.077 \\
\hline & $\mathrm{A} \beta^{2} * \mathrm{p}$-tau dichotomous & 0.015 & 0.008 & 1.74 & 0.083 \\
\hline
\end{tabular}

Note: Reported main effects do not include the interaction in the model. Covariates in all models were p-tau as dichotomous variable, age, sex, and MMSE score. Estimates are the unstandardized beta-coefficients. Interaction models (linear or quadratic $A \beta$ ) were independently tested for best model fit and only the best fitting model is reported here.
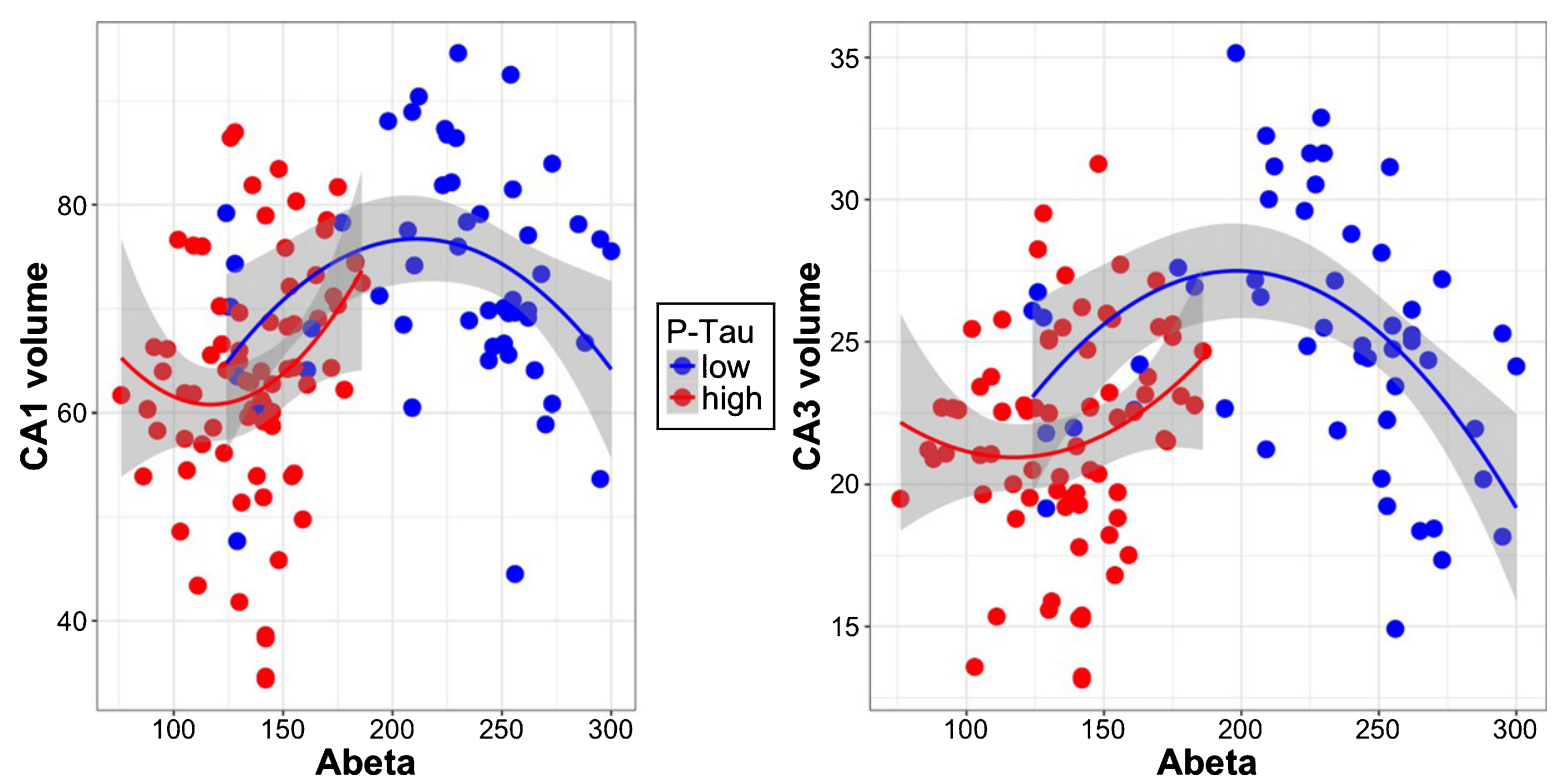

Fig. 4. Scatterplots showing the interaction between $A \beta$ and $p$-tau on subfield volumes $C A 1$ and $C A 3$. Volumes are corrected for intracranial volume. Participants with low p-tau (blue) have an inverted $\mathrm{u}$-shaped relationship of $\mathrm{A} \beta$ with subfield volume.

but were below the calculated inflection point $(218 \mathrm{mg} / \mathrm{pl})$ from the two-lines test differed significantly from the rest of the MCI population in having lower cognitive scores on the Rey Auditory Verbal Learning test immediate recall $(W=44.5, p=0.022)$ and lower p-tau levels $(W=32.5, p=0.011)$. There were no differences between cognitively normal participants between these cut-points and the rest of the cognitively normal sample (see Supplementary Table 4). 


\section{DISCUSSION}

The aim of the current study was to investigate the nature of the relationship between $A \beta$ and/or ptau and specific hippocampal subfield volumes, in a sample consisting of a broad range of pathology and cognitive functioning. Prior work showed nonlinear associations between $A \beta$ and cortical thinning, especially when tau levels are low [10]. Our study now extends these findings by showing distinct associations of $A \beta$ and p-tau on hippocampal subfield volumes. We observed additive associations of $A \beta$ and p-tau on CA4 and DG, suggesting that both biomarkers may have parallel influences on the structure of these subfields. The subiculum was mainly associated with $A \beta$ levels, which is consistent with the topography of $\mathrm{A} \beta$ in $\mathrm{AD}[2,16]$. In addition, nonlinear associations between $A \beta$ and CA1 or CA3 volume were observed in individuals with low levels of tau pathology, which is in line with previously reported findings on cortical thinning [10]. These findings contribute to a myriad of work indicating that brain regions may show distinct vulnerabilities to $A D$ pathology, which in turn has a progressive, non-linear impact on brain structure and function [37]. Such observations are crucial for the understanding of $\mathrm{AD}$ pathophysiological mechanisms, but also for detection of individuals at risk for disease progression, as we will discuss below.

Previous studies showed synergistic effects of $A \beta$ and tau on hippocampal atrophy [22] and cortical thinning, with elevated levels of tau accelerating the accumulation of $\mathrm{A} \beta$ in $\mathrm{AD}$ specific regions [38] and abnormal levels of $A \beta$ influencing tau propagation and tau-induced neuronal loss [39, 40], indicating that abnormalities in both biomarkers amplify aberrant neuronal processes. In the context of memory and AD-related memory deficits, the hippocampus is a crucial and interesting structure, as its subfields are involved in distinct memory processes [41, 42]. It is therefore intriguing that the subfield volumes show distinct associations with CSF biomarkers. Combining both $A \beta$ and p-tau in the same model revealed that in CA1 and CA3, areas crucially involved in episodic memory processes such as pattern separation and completion [41, 43], the relationship between $\mathrm{A} \beta$ and subfield volumes behaved non-linearly and is modified by p-tau. Pattern separation and completion are two core processes of episodic memory and rely heavily on the integrity of the CA1-CA3 circuitry, and disruptions of this circuit directly correlate with decreased performance on pattern separation tasks $[44,45]$. While this would be an interesting avenue to explore, ADNI unfortunately does not administer a memory discrimination task, and therefore, we are currently not able to directly investigate the link between pattern separation and biomarkers. Given the non-linear association, it would be interesting to assess at what level of $A \beta$ pathology, pattern separation, and CA1-CA3 volume are related. It is important to note though, that these deleterious effects by $\mathrm{A} \beta$ on $\mathrm{CA} 1$ and $\mathrm{CA} 3$ volume were most prominent when p-tau levels were low. The CA1 is among the first subfields to accumulate $A \beta$ depositions [46, 47] and $A \beta$ accumulation in the $\mathrm{CA} 3$ has been associated with disrupted hippocampal functioning [48]. Thus, possibly AD-related memory impairments may in part be due to early $A \beta$ accumulating in crucial subfields, in individuals whose tau pathology has not yet widely spread outside of the entorhinal cortex. This subfield-specific finding could be of potential benefit for improving early detection of persons at risk for developing AD-type dementia.

Our data suggests that the subiculum volume is mainly associated with $A \beta$ levels, independent of tau. Possibly, a closer inspection of the subiculum subregions at higher spatial resolution could provide a more elaborate view, as it has previously been reported that abnormal values of both $A \beta$ and $p$-tau influence posterior subicular atrophy in patients with cognitive complaints [49] and postmortem studies have indicated that the subiculum also accumulates tau in early stages [50].

The fact that we observed independent effect of $A \beta$ and $p$-tau on DG and CA4 volume may fit with the neuropathological notions of later involvement of these subfields. The DG and CA4 are affected by $\mathrm{A} \beta$ from Thal-stage III and higher [51] and p-tau depositions from NFT-stage IV/V [2]. Independent pathways of $A \beta$ and tau on structural neuroimaging markers, total hippocampal volume, ventricular volume, and FDG-PET have previously been described [52]. Possibly, the interaction between $A \beta$ and p-tau in DG and CA4 becomes less prominent with disease progression. Disease models suggest that with disease progression $A \beta$ reaches a plateau, whereas tau keeps increasing [37].

Overall, it is interesting that the associations between in vivo CSF biomarkers and specific hippocampal subfield volumes reflect, to some degree, the topography reported in the autopsy literature. It is important to note that we reported on crosssectional associations and hence, any inferences on 
disease-stage specific associations between biomarkers and hippocampal subfield volumes remain speculative. In addition to $A \beta$ and tau, hippocampal volume is also affected by other pathologies, such as vascular pathology, TDP-43, or hippocampal sclerosis. The fact that individuals around the validated cut-off point have higher subfield volumes than those further away from the cut-point may indicate a potential ongoing aberrant process, such as, for example, inflammatory responses $[6,53]$. If this hypothesis is true, then inflammation markers may signal increasing amyloid accumulation. It would be interesting for future studies to longitudinally track hippocampal volume along with biomarker data and inflammatory markers.

Finally, our results further spark the discussion on using $A \beta$ values continuously rather than dichotomously [9]. We observed that the inflection point for the $u$-shaped effect of $A \beta$ was overall higher than the validated cut-off for $A \beta$. Several recent studies using $A \beta$-PET and $A \beta$-CSF have also indicated that individuals whose $A \beta$ values are close to the cut-off but still normal show evidence of $A \beta$ accumulation, cognitive decline, and tau pathology $[9,54$, 55]. These results indicate that rates of accumulation of $\mathrm{A} \beta$ may better identify individuals at risk for $\mathrm{AD}$ than baseline levels or the use of a binary cut-off. This potentially may hold implications for clinicians, for whom patients within a specified range of $A \beta$ pathology (including individuals still considered normal) may be followed up more closely over time, as their clinical and biomarker trajectories can reveal critical prognostic information. Our results were performed at the cross-section, but it will be informative to investigate in larger and longitudinal studies if individuals around the inflection point accumulate $A \beta$ at a faster pace than those further away from the inflection point.

Interestingly, post-hoc inspection of the individuals in between the cut-off of $192 \mathrm{pg} / \mathrm{ml}$ to the calculated inflection point of $217.8 \mathrm{pg} / \mathrm{ml}(n=9$, $\mathrm{CN}=5, \mathrm{MCI}=4$ ), revealed that the 4 individuals with MCI had lower scores on all parts of the Rey Auditory learning Test and also lower p-tau-values as compared to the total MCI sample. The lower cognitive scores most likely contributed to their clinical diagnosis and it may well be that the biomarkers in these individuals are less abnormal because of the additive presence of comorbidities. This data is on par with other studies suggesting that pathologies or comorbidities can lower the threshold for cognitive decline associated with $\mathrm{AD}$ pathology. It may also indicate that the interpretation of accumulation rates of $A \beta$ should be done within the context of other risk factors.

As current clinical preventive trials are focusing on treating individuals as early as possible, dichotomizing biomarkers may lead to failed inclusions of individuals at risk for $\mathrm{AD}$ in clinical trials. A multimodal biomarker, combining MR-imaging such as detailed hippocampal subfield volumes, in combination with longitudinal $A \beta$ measures and possibly other markers, e.g., inflammation markers, may increase sensitivity to identify at-risk individuals in the asymptomatic phase.

\section{Limitations and future directions}

Because the hippocampal subfields processing pipeline, involving several checks and manual edits, is time consuming, and our selection criteria were based on the presence of longitudinal CSF data, we investigated a subsample of ADNI. The results may therefore not be generalizable to the entire sample or other cohorts. While our results are consistent with reports on cortical thickness, the specificity of hippocampal subfield regions should be replicated in larger samples, with more AD cases. In addition, longitudinal data will be necessary to understand the evolution of the positive association between $A \beta$ and volume in the individuals around the threshold and to determine whether this information does contain added value for diagnostic or predictive purposes.

The new development of tau PET tracers in combination with the $A \beta$ tracers will allow investigating regional differences of the associations between neurodegeneration and $\mathrm{A} \beta$ and/or tau in vivo [56]. However, the current spatial resolution constraints of PET will make it challenging to examine specific hippocampal subfields.

A complicating factor in the comparison of results of studies investigating hippocampal subfields are the methodological differences, which differ widely between protocols, ranging from manual segmentation [20,57] to half-automated [58] and fully automated [59] segmentation procedures and using different software packages. The advantages and disadvantages of different tools and techniques are discussed elsewhere [60] and a dedicated working group is currently active in harmonizing the various protocols to segment the hippocampal subfields to improve comparisons across different laboratories and software packages (http://www.hippocampalsubfields.com). 


\section{CONCLUSION}

CSF biomarkers $A \beta$ and $p$-tau both have distinct associations with hippocampal subfield-volumes. These biomarker relationships with hippocampal subfield volumes seem to reflect the hippocampalspecific topography of $A \beta$ and tau reported in neuropathological staging models. $A \beta$ and $p$-tau contribute independently to DG, CA4, subiculum, and total hippocampus volume. All subfields have a nonlinear relationship with $\mathrm{A} \beta$, and for the $\mathrm{CA} 3$ and $\mathrm{CA} 1$ this is observed in the context of low p-tau levels. Our results suggest that using continuous values of $A \beta$ reveals patterns with imaging markers that are not clear from dichotomization and can be important for early detection of individuals at risk for $\mathrm{AD}$ and for accurate inclusion of potential participants in clinical trials targeting $\mathrm{A} \beta$.

\section{ACKNOWLEDGMENTS}

This work was supported by a DFG individual grant JA 2336/1-1 (HILJ).

Freesurfer analyses were carried out on the Dutch national e-infrastructure with the support of SURF Cooperative and NWO Exact Sciences grant MP310-15 (HILJ \& JMR).

Data collection and sharing for this project was funded by the Alzheimer's Disease Neuroimaging Initiative (ADNI) (National Institutes of Health Grant U01 AG024904 ADNI is funded by the National Institute on Aging, the National Institute of Biomedical Imaging and Bioengineering, and through generous contributions from the following: AbbVie, Alzheimer's Association; Alzheimer's Drug Discovery Foundation; Araclon Biotech; BioClinica, Inc.; Biogen; Bristol-Myers Squibb Company; CereSpir, Inc.; Cogstate; Eisai Inc.; Elan Pharmaceuticals, Inc.; Eli Lilly and Company; EuroImmun; F. Hoffmann-La Roche Ltd and its affiliated company Genentech, Inc.; Fujirebio; GE Healthcare; IXICO Ltd.; Janssen Alzheimer Immunotherapy Research \& Development, LLC.; Johnson \& Johnson Pharmaceutical Research \& Development LLC.; Lumosity; Lundbeck; Merck \& Co., Inc.; Meso Scale Diagnostics, LLC.; NeuroRx Research; Neurotrack Technologies; Novartis Pharmaceuticals Corporation; Pfizer Inc.; Piramal Imaging; Servier; Takeda Pharmaceutical Company; and Transition Therapeutics. The Canadian Institutes of Health Research is providing funds to support ADNI clinical sites in
Canada. Private sector contributions are facilitated by the Foundation for the National Institutes of Health (http://www.fnih.org). The grantee organization is the Northern California Institute for Research and Education, and the study is coordinated by the Alzheimer's Therapeutic Research Institute at the University of Southern California. ADNI data are disseminated by the Laboratory for Neuro Imaging at the University of Southern California.

Authors' disclosures available online (https:// www.j-alz.com/manuscript-disclosures/18-0676r1).

\section{SUPPLEMENTARY MATERIAL}

The supplementary material is available in the electronic version of this article: http://dx.doi.org/ 10.3233/JAD-180676.

\section{REFERENCES}

[1] Burns A, Iliffe S (2009) Alzheimer's disease. BMJ 338, b158.

[2] Braak H, Braak E (1995) Staging of Alzheimer's diseaserelated neurofibrillary changes. Neurobiol Aging 16, 271278; discussion 278-284.

[3] Desikan RS, Sabuncu MR, Schmansky NJ, Reuter M, Cabral HJ, Hess CP, Weiner MW, Biffi A, Anderson CD, Rosand J, Salat DH, Kemper TL, Dale AM, Sperling RA, Fischl B, Alzheimer's Disease Neuroimaging Initiative (2010) Selective disruption of the cerebral neocortex in Alzheimer's disease. PLoS One 5, e12853.

[4] Dickerson BC, Wolk DA, Alzheimer's Disease Neuroimaging Initiative (2012) MRI cortical thickness biomarker predicts AD-like CSF and cognitive decline in normal adults. Neurology 78, 84-90.

[5] Ye BS, Seo SW, Kim CH, Jeon S, Kim GH, Noh Y, Cho $\mathrm{H}$, Yoon CW, Kim HJ, Jang EY, Lee J, Kim JH, Chin J, Lee JM, Kim JH, Seong JK, Kim CH, Choe YS, Lee $\mathrm{KH}$, Na DL (2014) Hippocampal and cortical atrophy in amyloid-negative mild cognitive impairments: Comparison with amyloid-positive mild cognitive impairment. Neurobiol Aging 35, 291-300.

[6] Fortea J, Sala-Llonch R, Bartres-Faz D, Bosch B, Llado A, Bargallo N, Molinuevo JL, Sanchez-Valle R (2010) Increased cortical thickness and caudate volume precede atrophy in PSEN1 mutation carriers. J Alzheimers Dis 22, 909-922.

[7] Fortea J, Sala-Llonch R, Bartrés-Faz D, Lladó A, SoléPadullés C, Bosch B, Antonell A, Olives J, Sanchez-Valle R, Molinuevo JL (2011) Cognitively preserved subjects with transitional cerebrospinal fluid $\beta$-amyloid 1-42 values have thicker cortex in Alzheimer's disease vulnerable areas. Biol Psychiatry 70, 183-190.

[8] de Leon MJ, Pirraglia E, Osorio RS, Glodzik L, Saint-Louis L, Kim H-J, Fortea J, Fossati S, Laska E, Siegel C (2018) The nonlinear relationship between cerebrospinal fluid $\mathrm{A} \beta 42$ and tau in preclinical Alzheimer's disease. PLoS One 13, e0191240.

[9] Tijms BM, Bertens D, Slot RE, Gouw AA, Teunissen CE, Scheltens P, van der Flier WM, Visser PJ (2017) Low normal 
cerebrospinal fluid Abeta42 levels predict clinical progression in nondemented subjects. Ann Neurol 81, 749-753.

[10] Fortea J, Vilaplana E, Alcolea D, Carmona-Iragui M, Sanchez-Saudinos MB, Sala I, Anton-Aguirre S, Gonzalez S, Medrano S, Pegueroles J, Morenas E, Clarimon J, Blesa R, Lleo A, Alzheimer's Disease Neuroimaging Initiative (2014) Cerebrospinal fluid beta-amyloid and phospho-tau biomarker interactions affecting brain structure in preclinical Alzheimer disease. Ann Neurol 76, 223-230.

[11] d'Oleire Uquillas F, Jacobs HIL, Hanseeuw B, Marshall GA, Properzi M, Schultz AP, LaPoint MR, Johnson KA, Sperling RA, Vannini P (2018) Interactive versus additive relationships between regional cortical thinning and amyloid burden in predicting clinical decline in mild $\mathrm{AD}$ and MCI individuals. Neuroimage Clin 17, 388-396.

[12] Nelson PT, Alafuzoff I, Bigio EH, Bouras C, Braak H, Cairns NJ, Castellani RJ, Crain BJ, Davies P, Del Tredici K, Duyckaerts C, Frosch MP, Haroutunian V, Hof PR, Hulette CM, Hyman BT, Iwatsubo T, Jellinger KA, Jicha GA, Kovari E, Kukull WA, Leverenz JB, Love S, Mackenzie IR, Mann DM, Masliah E, McKee AC, Montine TJ, Morris JC, Schneider JA, Sonnen JA, Thal DR, Trojanowski JQ, Troncoso JC, Wisniewski T, Woltjer RL, Beach TG (2012) Correlation of Alzheimer disease neuropathologic changes with cognitive status: A review of the literature. J Neuropathol Exp Neurol 71, 362-381.

[13] Raskin J, Cummings J, Hardy J, Schuh K, Dean RA (2015) Neurobiology of Alzheimer's disease: Integrated molecular, physiological, anatomical, biomarker, and cognitive dimensions. Curr Alzheimer Res 12, 712-722.

[14] Zhou XW, Li X, Bjorkdahl C, Sjogren MJ, Alafuzoff I, Soininen H, Grundke-Iqbal I, Iqbal K, Winblad B, Pei JJ (2006) Assessments of the accumulation severities of amyloid beta-protein and hyperphosphorylated tau in the medial temporal cortex of control and Alzheimer's brains. Neurobiol Dis 22, 657-668.

[15] Braak H, Braak E, Bohl J (1993) Staging of Alzheimerrelated cortical destruction. Eur Neurol 33, 403-408.

[16] Apostolova LG, Zarow C, Biado K, Hurtz S, Boccardi $\mathrm{M}$, Somme J, Honarpisheh $\mathrm{H}$, Blanken AE, Brook J, Tung S, Lo D, Ng D, Alger JR, Vinters HV, Bocchetta M, Duvernoy H, Jack CR Jr, Frisoni GB; EADC-ADNI Working Group on the Harmonized Protocol for Manual Hippocampal Segmentation (2015) Relationship between hippocampal atrophy and neuropathology markers: A 7T MRI validation study of the EADC-ADNI Harmonized Hippocampal Segmentation Protocol. Alzheimers Dement 11, 139-150.

[17] de Souza LC, Chupin M, Lamari F, Jardel C, Leclercq D, Colliot O, Lehericy S, Dubois B, Sarazin M (2012) CSF tau markers are correlated with hippocampal volume in Alzheimer's disease. Neurobiol Aging 33, 1253-1257.

[18] Huijbers W, Mormino EC, Schultz AP, Wigman S, Ward AM, Larvie M, Amariglio RE, Marshall GA, Rentz DM, Johnson KA, Sperling RA (2015) Amyloid-beta deposition in mild cognitive impairment is associated with increased hippocampal activity, atrophy and clinical progression. Brain 138, 1023-1035.

[19] La Joie R, Perrotin A, De La Sayette V, Egret S, Doeuvre L, Belliard S, Eustache F, Desgranges B, Chételat G (2013) Hippocampal subfield volumetry in mild cognitive impairment, Alzheimer's disease and semantic dementia. Neuroimage Clin 3, 155-162.

[20] Hsu PJ, Shou H, Benzinger T, Marcus D, Durbin T, Morris JC, Sheline YI (2015) Amyloid burden in cognitively normal elderly is associated with preferential hippocampal subfield volume loss. J Alzheimers Dis 45, 27-33.

[21] Tardif CL, Devenyi GA, Amaral RSC, Pelleieux S, Poirier J, Rosa-Neto P, Breitner J, Chakravarty MM, Group PAR (2018) Regionally specific changes in the hippocampal circuitry accompany progression of cerebrospinal fluid biomarkers in preclinical Alzheimer's disease. Hum Brain Mapp 39, 971-984.

[22] Stricker NH, Dodge HH, Dowling NM, Han SD, Erosheva EA, Jagust WJ, Alzheimer's Disease Neuroimaging Initiative (2012) CSF biomarker associations with change in hippocampal volume and precuneus thickness: Implications for the Alzheimer's pathological cascade. Brain Imaging Behav 6, 599-609.

[23] Petersen RC, Aisen PS, Beckett LA, Donohue MC, Gamst AC, Harvey DJ, Jack CR Jr, Jagust WJ, Shaw LM, Toga AW, Trojanowski JQ, Weiner MW (2010) Alzheimer's Disease Neuroimaging Initiative (ADNI): Clinical characterization. Neurology 74, 201-209.

[24] Shaw LM, Vanderstichele H, Knapik-Czajka M, Figurski M, Coart E, Blennow K, Soares H, Simon AJ, Lewczuk P, Dean RA, Siemers E, Potter W, Lee VM, Trojanowski JQ, Alzheimer's Disease Neuroimaging Initiative (2011) Qualification of the analytical and clinical performance of CSF biomarker analyses in ADNI. Acta Neuropathol 121, 597-609.

[25] Hampel H, Blennow K, Shaw LM, Hoessler YC, Zetterberg H, Trojanowski JQ (2010) Total and phosphorylated tau protein as biological markers of Alzheimer's disease. Exp Gerontol 45, 30-40.

[26] Iglesias JE, Augustinack JC, Nguyen K, Player CM, Player A, Wright M, Roy N, Frosch MP, McKee AC, Wald LL, Fischl B, Van Leemput K, Alzheimer's Disease Neuroimaging Initiative (2015) A computational atlas of the hippocampal formation using ex vivo, ultra-high resolution MRI: Application to adaptive segmentation of in vivo MRI. Neuroimage 115, 117-137.

[27] Fischl B (2012) FreeSurfer. Neuroimage 62, 774-781.

[28] Fischl B, Sereno MI, Dale AM (1999) Cortical surfacebased analysis. II: Inflation, flattening, and a surface-based coordinate system. Neuroimage $\mathbf{9}, 195-207$.

[29] Dale AM, Fischl B, Sereno MI (1999) Cortical surfacebased analysis. I. Segmentation and surface reconstruction. Neuroimage 9, 179-194.

[30] Reuter M, Fischl B (2011) Avoiding asymmetry-induced bias in longitudinal image processing. Neuroimage 57, 19-21.

[31] Reuter M, Rosas HD, Fischl B (2010) Highly accurate inverse consistent registration: A robust approach. Neuroimage 53, 1181-1196.

[32] Iglesias JE, Augustinack JC, Nguyen K, Player CM, Player A, Wright M, Roy N, Frosch MP, McKee AC, Wald LL (2015) A computational atlas of the hippocampal formation using ex vivo, ultra-high resolution MRI: Application to adaptive segmentation of in vivo MRI. Neuroimage 115, 117-137.

[33] Apostolova LG, Mosconi L, Thompson PM, Green AE, Hwang KS, Ramirez A, Mistur R, Tsui WH, de Leon MJ (2010) Subregional hippocampal atrophy predicts Alzheimer's dementia in the cognitively normal. Neurobiol Aging 31, 1077-1088.

[34] Daugherty AM, Bender AR, Raz N, Ofen N (2016) Age differences in hippocampal subfield volumes from childhood to late adulthood. Hippocampus 26, 220-228. 
[35] Simonsohn U (2017) Two-lines: The first valid test of Ushaped relationships.

[36] Benjamini Y, Hochberg Y (1995) Controlling the false discovery rate: A practical and powerful approach to multiple testing. J R Stat Soc Series B Stat Methodol 57, 289-300.

[37] Jack CR Jr, Holtzman DM (2013) Biomarker modeling of Alzheimer's disease. Neuron 80, 1347-1358.

[38] Desikan RS, McEvoy LK, Thompson WK, Holland D, Roddey JC, Blennow K, Aisen PS, Brewer JB, Hyman BT, Dale AM, Alzheimer's Disease Neuroimaging Initiative (2011) Amyloid-beta associated volume loss occurs only in the presence of phospho-tau. Ann Neurol 70, 657-661.

[39] Pooler AM, Polydoro M, Maury EA, Nicholls SB, Reddy SM, Wegmann S, William C, Saqran L, Cagsal-Getkin O, Pitstick R, Beier DR, Carlson GA, Spires-Jones TL, Hyman BT (2015) Amyloid accelerates tau propagation and toxicity in a model of early Alzheimer's disease. Acta Neuropathol Commun 3, 14.

[40] Jacobs HIL, Hedden T, Schultz AP, Sepulcre J, Perea RD, Amariglio RE, Papp KV, Rentz DM, Sperling RA, Johnson KA (2018) Structural tract alterations predict downstream tau accumulation in amyloid-positive older individuals. Nat Neurosci 21, 424-431.

[41] Yassa MA, Stark CE (2011) Pattern separation in the hippocampus. Trends Neurosci 34, 515-525.

[42] Doxey CR, Kirwan CB (2015) Structural and functional correlates of behavioral pattern separation in the hippocampus and medial temporal lobe. Hippocampus 25, 524-533.

[43] Lacy JW, Yassa MA, Stark SM, Muftuler LT, Stark CEL (2011) Distinct pattern separation related transfer functions in human CA3/dentate and CA1 revealed using highresolution fMRI and variable mnemonic similarity. Learn Mem 18, 15-18.

[44] Yassa MA, Mattfeld AT, Stark SM, Stark CE (2011) Agerelated memory deficits linked to circuit-specific disruptions in the hippocampus. Proc Natl Acad Sci U S A 108, 88738878.

[45] Stark SM, Yassa MA, Lacy JW, Stark CE (2013) A task to assess behavioral pattern separation (BPS) in humans: Data from healthy aging and mild cognitive impairment. Neuropsychologia 51, 2442-2449.

[46] Braak H, Braak E (1997) Frequency of stages of Alzheimerrelated lesions in different age categories. Neurobiol Aging 18, 351-357.

[47] Apostolova LG, Hwang KS, Andrawis JP, Green AE, Babakchanian S, Morra JH, Cummings JL, Toga AW, Trojanowski JQ, Shaw LM, Jack CR, Jr., Petersen RC, Aisen PS, Jagust WJ, Koeppe RA, Mathis CA, Weiner MW, Thompson PM, Alzheimer's Disease Neuroimaging Initiative (2010) 3D PIB and CSF biomarker associations with hippocampal atrophy in ADNI subjects. Neurobiol Aging 31, 1284-1303.

[48] Nava-Mesa MO, Jimenez-Diaz L, Yajeya J, Navarro-Lopez JD (2013) Amyloid-beta induces synaptic dysfunction through $G$ protein-gated inwardly rectifying potassium channels in the fimbria-CA3 hippocampal synapse. Front Cell Neurosci 7, 117.

[49] Lindberg O, Mårtensson G, Stomrud E, Palmqvist S, Wahlund L-O, Westman E, Hansson O (2017) Atrophy of the posterior subiculum is associated with memory impairment, tau-and $\mathrm{A} \beta$ pathology in non-demented individuals. Front Aging Neurosci 9, 306.

[50] Thal DR, Holzer M, Rub U, Waldmann G, Gunzel S, Zedlick D, Schober R (2000) Alzheimer-related tau-pathology in the perforant path target zone and in the hippocampal stratum oriens and radiatum correlates with onset and degree of dementia. Exp Neurol 163, 98-110.

[51] Thal DR, Rub U, Orantes M, Braak H (2002) Phases of A beta-deposition in the human brain and its relevance for the development of AD. Neurology 58, 1791-1800.

[52] Han SD, Gruhl J, Beckett L, Dodge HH, Stricker NH, Farias $\mathrm{S}$, Mungas D, Alzheimer's Disease Neuroimaging Initiative (2012) Beta amyloid, tau, neuroimaging, and cognition: Sequence modeling of biomarkers for Alzheimer's disease. Brain Imaging Behav 6, 610-620.

[53] Jacobs HI, Clerx L, Gronenschild EH, Aalten P, Verhey FR (2014) White matter hyperintensities are positively associated with cortical thickness in Alzheimer's disease. $J$ Alzheimers Dis 39, 409-422.

[54] Landau SM, Horng A, Jagust WJ, Alzheimer's Disease Neuroimaging Initiative (2018) Memory decline accompanies subthreshold amyloid accumulation. Neurology 90, e1452e1460.

[55] Leal SL, Lockhart SN, Maass A, Bell RK, Jagust WJ (2018) Subthreshold amyloid predicts tau deposition in aging. J Neurosci 38, 4482-4484.

[56] Scholl M, Lockhart SN, Schonhaut DR, O’Neil JP, Janabi M, Ossenkoppele R, Baker SL, Vogel JW, Faria J, Schwimmer HD, Rabinovici GD, Jagust WJ (2016) PET imaging of tau deposition in the aging human brain. Neuron 89, 971-982.

[57] Mueller SG, Schuff N, Yaffe K, Madison C, Miller B, Weiner MW (2010) Hippocampal atrophy patterns in mild cognitive impairment and Alzheimer's disease. Hum Brain Mapp 31, 1339-1347.

[58] Hanseeuw BJ, Van Leemput K, Kavec M, Grandin C, Seron X, Ivanoiu A (2011) Mild cognitive impairment: Differential atrophy in the hippocampal subfields. AJNR Am J Neuroradiol 32, 1658-1661.

[59] Cantero JL, Iglesias JE, Van Leemput K, Atienza M (2016) Regional hippocampal atrophy and higher levels of plasma amyloid-beta are associated with subjective memory complaints in nondemented elderly subjects. J Gerontol A Biol Sci Med Sci 71, 1210-1215.

[60] Wisse LE, Daugherty AM, Olsen RK, Berron D, Carr VA, Stark CE, Amaral RS, Amunts K, Augustinack JC, Bender AR (2017) A harmonized segmentation protocol for hippocampal and parahippocampal subregions: Why do we need one and what are the key goals? Hippocampus 27, 3-11. 